\title{
Effects of aerosol dynamics and gas-particle conversion on dry deposition of inorganic reactive nitrogen in a temperate forest
}

Genki Katata et al.

Correspondence to: Genki Katata (genki.katata.mirai@vc.ibaraki.ac.jp)

The copyright of individual parts of the supplement might differ from the CC BY 4.0 License. 
(a) $\mathrm{U}$

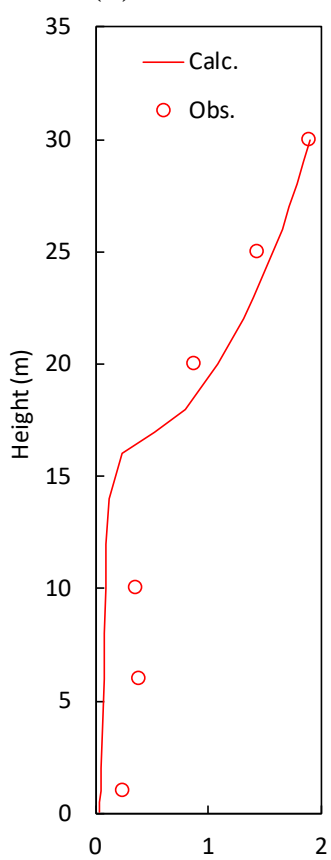

(d) $U$

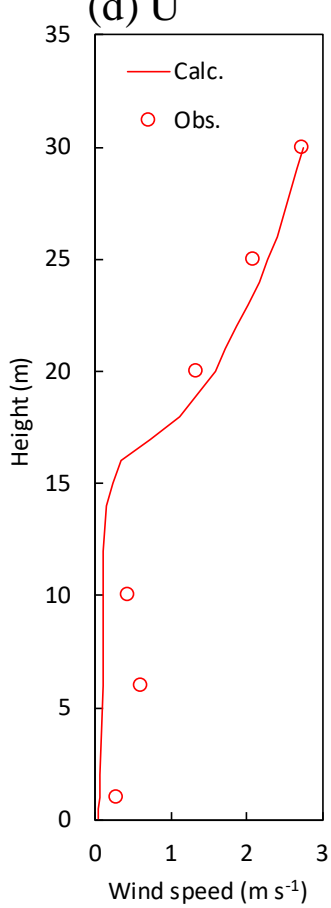

(b) $\mathrm{T}$

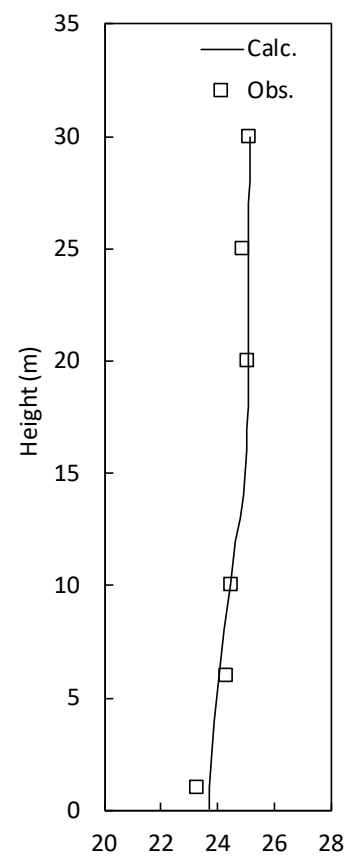

(e) $\mathrm{T}$

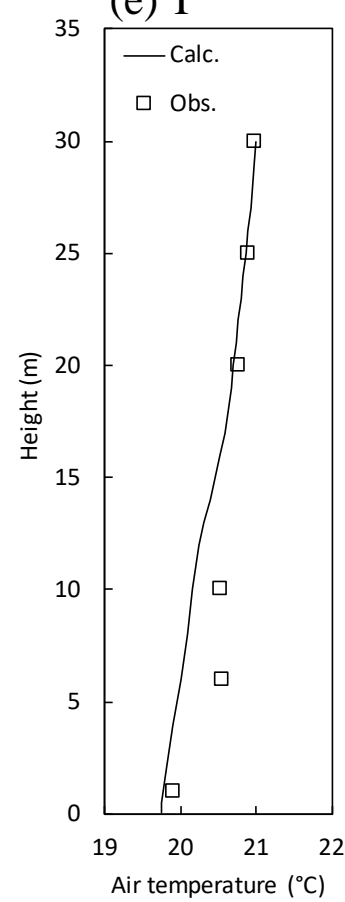

(c) $\mathrm{RH}$
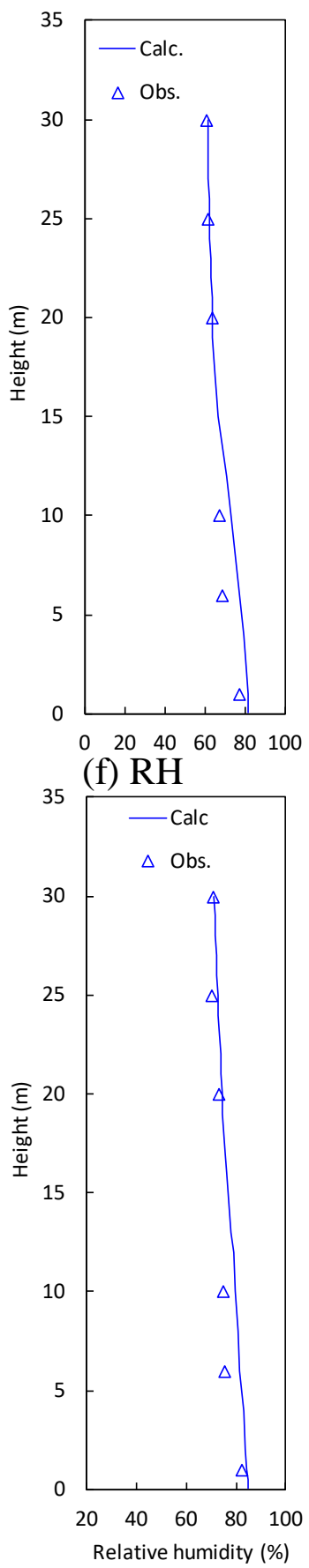

2

3 Figure S1. Mean vertical profiles in observed and calculated (a) wind speed, (b) air temperature, 4 and (c) relative humidity in all simulation scenarios $(\mathrm{a}-\mathrm{c})$ during the daytime and $(\mathrm{d}-\mathrm{f})$ 5 nighttime between 27 September and 11 October 2016 except for grey shaded areas in Fig. 6. 

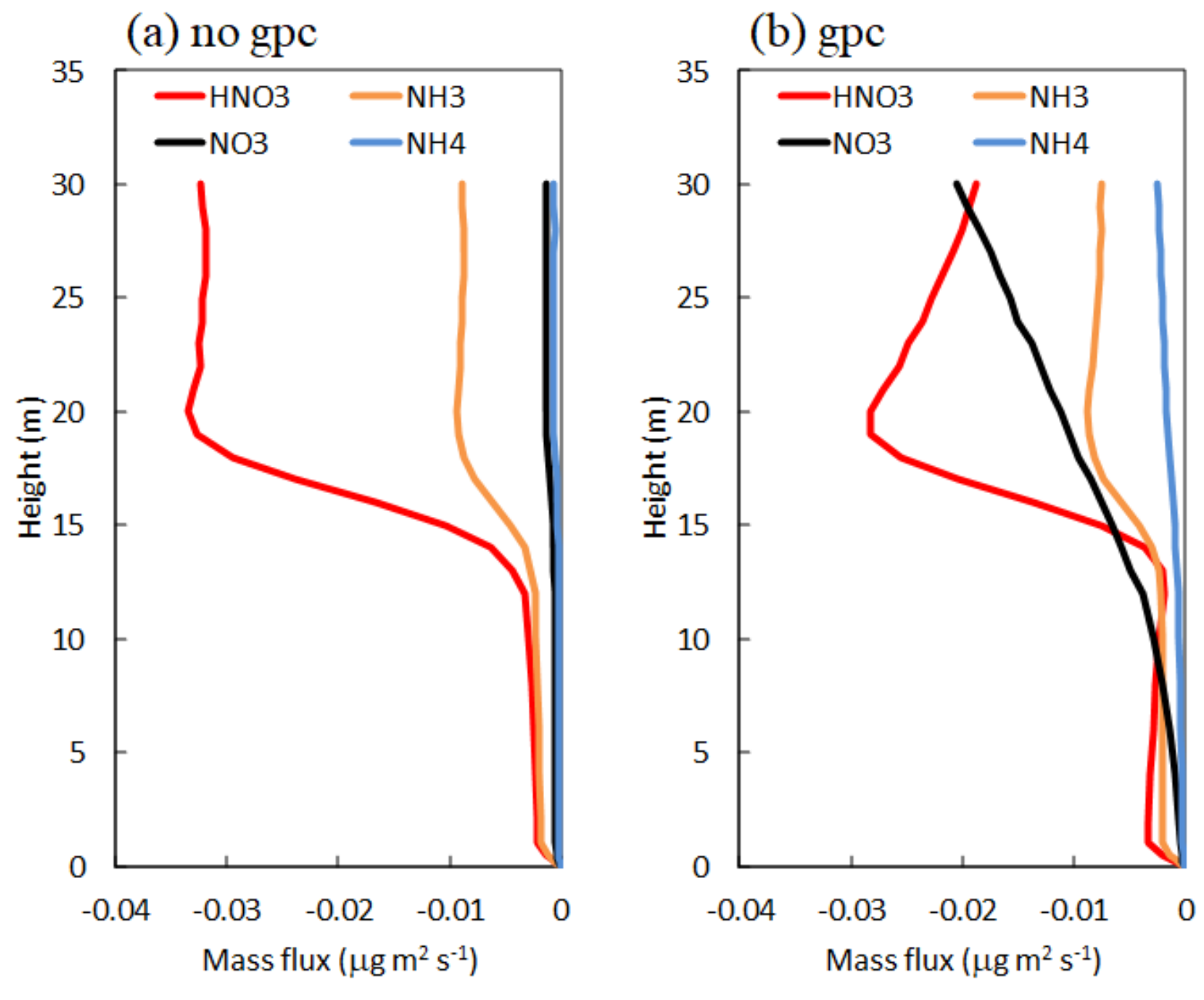

8 Figure S2. Mean vertical profiles in (a) calculated normalized mass flux in the "no gpc" scenario 9 and (b) the "gpc" scenario for $\mathrm{HNO}_{3}$ and $\mathrm{NH}_{3}$ gases and $\mathrm{NO}_{3}{ }^{-}$and $\mathrm{NH}_{4}{ }^{+}$fine particles during 10 the daytime between 27 September and 11 October 2016 except for grey shaded areas in Fig. 6. 
Table S1. Summary of simulation settings for the multi-layer atmosphere-SOiL-VEGetation model, SOLVEG.

16

Item Value

Simulation periods

Early autumn (26 September to 11 October 2016);

Late autumn: 7 November to 7 December

Time step

$6 \mathrm{~s}$

Vegetation species

Broad-leaved forest (Quercus spp.)

Numbers of layers

29, 20, and 7 for atmosphere, vegetation, and soil, respectively

Soil layer boundaries $0.02,0.05,0.1,0.2,0.5,1.0$, and $2.0 \mathrm{~m}$ depth

Vegetation layer boundaries

$0.05,0.1,0.2,0.3$, and $0.5 \mathrm{~m}$ (understory vegetation), and from 1 to $20 \mathrm{~m}$ (forest canopy) with an increment of $1 \mathrm{~m}$

Atmospheric layer boundaries At the vegetation layers and from heights of 21 to $29 \mathrm{~m}$ in increments of $0.1 \mathrm{~m}$

Root fraction distribution Constant from the surface to $0.5 \mathrm{~m}$ depth

Characteristics length for leaf,10 mm

$d_{\text {leaf }}$

Number of particle size bins 30 bins from 0.003 to $3.5 \mu \mathrm{m}$ in diameter

Porosity (saturated water $0.43 \mathrm{~m}^{3} \mathrm{~m}^{-3}$

content)

Soil texture Loam

Initial soil water content $\quad 0.5 \mathrm{~m}^{3} \mathrm{~m}^{-3}$

Leaf area index (LAI) of trees 4.3 (early autumn) and $3.6 \mathrm{~m}^{2} \mathrm{~m}^{-3}$ (late autumn)

Other parameters Same as Katata et al. (2014) 


\section{References}

20

Katata, G., Kajino, M., Matsuda, K., Takahashi, A., and Nakaya, K.: A numerical study of the effects of aerosol hygroscopic properties to dry deposition on a broad-leaved forest, Atmos. Environ., 97, 501-510, 2014.

23 